\title{
Application of Trenchless Construction Technology in Construction of Water Supply and Drainage in Urban Road Construction
}

\author{
Tie Sinna
}

Zhengzhou City Tunnel Integrated Management and Maintenance Center Zhengzhou City, Henan Province

Abstract: With the development of society, for the laying and repairing of urban drainage pipes system has been from the excavation technology operation and gradually transformed into trenchless technology operation. In this paper, the application of trenchless construction technology for urban road construction is studied, and the introduction, characteristics, scope and measures of trenchless construction in urban road construction are discussed.

Keywords: urban road; drainage construction; trenchless technology; construction

\section{Introduction}

Trenchless technology refers to non-excavation and less excavation of the case, the underground pipes or pipelines being maintained and replaced, which belongs to the exploration of the construction technology. Trenchless technology, due to its non-excavation construction characteristics, to the maintenance work has brought great convenience, it is widely used in highways, urban roads, railways, buildings, lakes, ancient cultural relics maintenance and laying process. The application of trenchless technology to promote the development of urban road pipeline construction.

\section{The introduction and characteristics of trenchless technology}

\subsection{The introduction of trenchless technology}

Trenchless technology, the application of a larger range of environmental protection areas can also be used. In comparison of trenchless technology and conventional excavation pipeline construction technology, trenchless technology has certain advantages. Conventional excavation pipeline construction technology has the characteristics of simple operation, obvious effect, mature technology and no technical risk. The state has a clear provision in the pipeline repair process requires a water supply operation in order to avoid waste of water and bring trouble to the construction. Therefore, the repair process with less time consuming, the quality of pipeline maintenance is better, the residents of the normal use of less water maintenance methods, the country is strongly supported ${ }^{[1]}$. However, conventional excavation pipeline construction technology has a certain destructive, it will damage the original construction, affecting the traffic environment, destruction of natural structure, resulting in a lot of dust and serious air pollution. The use of conventional excavation pipeline con- struction technology maintenance section takes a long time to restore the original appearance.

Copyright (C) 2016 Tie SN

doi: 10.18686/utc.v3.23

This is an Open Access article distributed under the terms of the Creative Commons Attribution-Non Commercial 4.0 International License (http://creativecommons.org/ licenses/by-nc/4.0/), permitting all non-commercial use, distribution, and reproduction in any medium, provided the original work is properly cited. 
Trenchless technology, just to make up for the shortcomings of conventional excavation technology, it will not cause interference to the residents, it will not cause damage to the construction area which is conducive to natural environmental protection. Therefore, trenchless technology is more advantageous than the conventional excavation pipeline construction technology

\subsection{The characteristics of water supply and drainage trenchless technology}

Water supply and drainage trenchless technology is widely used in a variety of soil and construction is very convenient to facilitate the operation of the construction staff. Trenchless technology, Before the construction is carried out, the construction site should be checked, the construction line and the program plan, do all the preparation before the construction. Do the pre-construction preparation can save time and avoid the construction process has repeatedly modified the phenomenon of construction lines ${ }^{[2]}$. Trenchless technology in the construction process, the use of drilling rig, its operation is relatively simple and able to organize the construction. Urban road water supply and drainage construction construction using trenchless technology, its impact on the environment is very small, the construction process will not produce noise and dust, has an important role in environmental protection. The trenchless technology has less damage to the landform environment and less impact on the urban traffic environment. Trenchless technology in the application process construction speed faster, high efficiency and good construction quality. The use of rigs is the key to non-excavation technology. The scope of application of drilling rigs is very wide and the requirements for geology are very low. Instead of manual operation, the time cost and labor cost are saved and the construction unit can create more benefits. Trenchless technology, do not need to use earthwork for filling, having high safety performance. With the use of trenchless technology, construction workers only need to operate on the ground, you can complete the urban road construction to provide greater convenience for the staff and the construction safety factor is high, which can ensure the safety of the construction workers. Welding operation of trenchless construction is also completed on the ground, which can facilitate the construction staff to better control the quality of welding and facilitate the operation of personnel.

\section{The urban road construction water supply and drainage construction trenchless technology application range}

\subsection{Pipeline repair technology}

Urban road construction, water supply and drainage trenchless technology in the construction process, the need for pipeline maintenance, replacement, repair, and thus to maintain the safety of the pipeline. Pipeline repair technology, mainly on the occurrence of damage and leakage of the pipeline to repair, so that it can be used normally. For the repair of the pipeline, usually using external anti-corrosion repair technology and internal repair technology two methods. For the repair of the pipeline, the use of water pressure and air pressure lining material, the composite hose flipped lining the inner wall of the pipe to flip, and then through the hot water and steam to make it harder, so as to better repair the inner wall of the pipeline. Pipeline repair, you can use PE material, which has a good use of the characteristics of the old pipe lining repair has a certain role. PE material used for pipeline repair, the use of high-pressure grab water technology, the pipeline inside the fouling and impurities to rinse, remove the dirt inside the pipeline to keep the pipeline clean, so that the pipeline back to its original state. For the repair of the pipe knife, you can also use this technology, resulting in stainless steel version of the mold lining to improve the service life of the pipeline to enhance its corrosion resistance. 


\subsection{Pipeline replacement}

For the replacement of urban road pipelines, the use of bursting method is usually used. Burst pipe method is the country's most widely used replacement method, in fact, the cone of the tube tool, inserted into the need to replace the old pipe, the use of tension or thrust to break or through the pipeline, so as to achieve pipeline rupture the goal of broken pipe debris, fall into the surrounding soil, and the new pipe connected with the burst head through the tension and thrust, placed to the original position of the old pipe, thus completing the replacement of the pipeline. In the micro-tunneling method, commonly used to a method of tube eating, also known as in situ pipeline replacement method. The tube eating method mainly is to use a special tunnel boring machine, along the direction of the old pipe undergo its operation and then installation of larger diameter pipe. Tube eating method can improve the pipeline transport capacity, mainly in the underground buried depth of the larger sewage pipes. Pipeline replacement using trenchless technology can be based on the characteristics of the pipeline to take the appropriate technical means to facilitate the replacement of the pipeline.

\subsection{Pipeline laying}

Pipeline laying, using trenchless technology for construction. In the course of the operation, the use of guide rails and power tight top iron will support the back of the pit in the hydraulic jack on the tube into the soil and the tube of the soil to remove the dirt away. The first section of the tube into the soil all the way, the second section of the tube to continue into the operation, followed by the cycle of all the soil into the soil and make the interface to connect, so as to complete the pipeline laying. Trenchless technology, especially suitable for lakes, rivers and ancient buildings repair. The use of trenchless technology, pipeline laying can improve work efficiency, reduce working hours, to facilitate the operation of the staff, the impact on the environment is small and will not produce a greater noise and dust.

\section{Urban road construction water supply and drainage construction trenchless technology application}

\subsection{The application of trenchless technology in the laying of new pipelines}

Urban road construction water supply and drainage construction process, the use of trenchless technology, mainly the use of horizontal-oriented drilling method, ramming method, and shield method, pipe jacking operation to lay a new pipeline. Old pipeline repair mainly using the original fixed technology and winding technology to operate.

\subsubsection{Ramming method Horizontal-oriented drilling method}

Horizontal-oriented drilling method, is a more common new pipeline laying technology, which does not need to be excavated to achieve pipeline laying. Horizontal-oriented drilling method is based on the development of control technology and drilling technology, in the use of modern science and technology combined with the development of new technology and it is a trenchless technology ${ }^{[3]}$. Horizontal-oriented drilling method works, according to the pipeline has been set up lines, the use of wedge-shaped drill with a drill, its drill pipe embedded in the ground, and then according to the planning direction, through the computer control, bypass obstacles carry forward until you travel to your destination. In this case, it is necessary to remove the drill bit and install a special type of suitable return reamer to enable it to complete the drilling of the drill pipe to the desired diameter, the pipe to be used for laying holes entrance, so as to avoid the operation process, due to lack of space caused by pipe wear or damage. In the hole operation, the need to pay attention to join the chemical mud, to prevent the collapse while the drilling process. The work of the horizontal guided drilling method is mainly: construction preparation - measuring positioning - drilling machine in place - guide 
hole drilling - reaming - pull the pipeline - check the masonry - work pit backfill - landform recovery. The main mechanical equipment used in the construction of the project are: guided drilling machine, navigator, auxiliary boosting device, pipeline detector, electric detector, ramming equipment and so on. Horizontal-oriented drilling method, can be on the PVC pipe, PE pipe and other pipes for rigid connection. It should be noted that, before the laying of the pipeline, the need for pipe connections on the ground, the curve of the borrowing angle for the degree of drilling the longest distance of 800 meters, guided positioning system can survey the deepest level of 30 meters, in this range of construction operations. Horizontal guided drilling method, the main advantage of the construction can be encountered in the timely treatment of the problem and to simplify, so as to ensure the construction of the project. If the process of drilling and reaming, encountered huge stones, and other obstacles, this time will lead to the channel cannot form a straight line, need to re-punch operation, the new punch will not lead to material loss ${ }^{[4]}$. Horizontal-oriented drilling method, with a certain degree of limitations, the construction site has a higher demand, the need to lay the pipeline to leave a certain amount of space, to place the drill and the next pipe pit excavation. If the distance from the building is very close, and there is no under the excavation of the area, it is not suitable for the use of horizontal guided drilling method for the laying of new pipes.

\subsubsection{Ramming method}

Ramming method, mainly the use of pneumatic rammer hammer, the need to lay the steel pipe embedded in the formation, it should be noted that the pneumatic rammer hammer need to use low-frequency, large impact. China's use of ramming equipment, mainly imported in foreign countries, the scope can be laid more than two meters in diameter. The length of less than 100 meters of various types of steel pipe. Compared with the horizontal guided drilling method, the ramming method is relatively low. It is only necessary to have the ability to carry out the next pipe can be, can effectively lay the larger diameter of the steel pipe, and simple operation, high efficiency. The use of ramming method for construction, the need to use the main equipment, air compressor, engine resistance, ramming hammer and so on. In the operation, the latter part of the steel pipe is mainly to undertake the role of steel pipe hammer, and then through the power of steel pipe to the front of the tube boots on the theft of clods, the operation process needs to overcome the role of pipe and soil force, the steel pipe embedded in the ground. With the embedded steel pipe, the soil will be cut into the steel pipe, the first section of the steel pipe into the underground, the second section of steel pipe to continue to embed, do the connection between the steel pipe interface, until the last section of the steel pipe completely embedded, and then using compressed air, auger drill pipe, or artificial excavation method, the steel pipe in the cleanup. The application process of the ramming method, the direction of the tube, the angle and the height control, need to be measured by the theodolite and the level, so as to ensure the accuracy of the next tube. Ramming method, repair fluid is the use of dynamic load ramming, no back support, even in the construction process does not carry out soil operation and it will not collapse. Ramming method can be applied to different terrain and has the characteristics of short construction period. Ramming method are having some shortcomings, such as it can only be laid steel pipe, cannot carry out other work; by the length of construction restrictions, can only lay a range of 100 meters; if encountered complex soil, encountered a larger of the stone, ramming method cannot be used, embedded in the ground pipe cannot pull out, it will cause material loss.

\subsubsection{Shield method}

Shield method, the main use of the shield equipment. Shield refers to the front of the tunneling, rear-end lining equipment. The housing is made of steel material, mainly composed of cutting ring, support ring, lining ring, in which 
the cutting ring is located in the front of the shield, the support ring is located in the middle of the shield, and lining ring is located in the tail of the shield. Cutting for the role of protection, through the edge of the blade into the soil, and then use artificial or mechanical excavation in the excavation. Support the internal ring, the installation of hydraulic jacks with the driving force of the device. The front end of the jack is fixed in the cutting switch, after the cutting to complete the excavation work, the jack to push the shield forward. If the jack back after the mechanical energy contraction, it will reveal the lining ring ${ }^{[5]}$. The use of mechanical or artificial lining prefabricated cut, need to be carried out in the lining ring. When the lining is completed, the jack again blocks the block as a back, drags the shield forward, carries on the next lining with the excavation operation, and as a result of this cycle.

\subsubsection{Pipe jacking method}

Pipe jacking is a kind of trenchless technology, this technology used in the shield after the R \& D technology, which can be in the diameter of $600 \mathrm{~mm}-4000 \mathrm{~mm}$ within the pipeline laying. China has been used before the pipe laying method of pipe laying, earlier pipe jacking method as a special method, it will not be easy to use. Today, the use of pipe jacking is more common, recognized by the owners. The main application of pipe jacking and sewer construction, with the progress of society, the application of pipe jacking method gradually expanded. Its scope of application is, water pipes, gas pipes, and power cables, the future will continue to expand the application areas. Pipe jacking method has certain advantages, its impact on traffic is small, for the construction of urban roads is very important. The pipe jacking method can facilitate the construction of the city traffic without breaking the traffic.

\subsection{The application of trenchless technology in repairing old pipelines}

\subsubsection{In situ curing method}

The application of trenchless technology in the repair of old pipelines to promote the development of pipeline repair industry, saving the time and cost of pipeline repair, for the pipeline repair work has brought great convenience. In situ curing method, is the technology brought from the British into China, mainly used in the United Kingdom sewer repair. In situ curing method of development, initially it is only as a common pipeline construction method, without damaging the soil in the case of the pipeline for maintenance. With the development of society, this technology has been applied in China, and on this basis for the development of China's most commonly used for the pipeline maintenance. In-situ curing method, can be deal with different shapes and different sizes of the pipeline to repair. In situ curing method, suitable for diameter in the range of $100 \mathrm{~mm}-3000 \mathrm{~mm}$ pipeline. Its operating principle is mainly in the old pipe wall coated with a layer of liquid thermosetting resin, the use of heat curing agent to form a tightly combined with the old pipe wall of a layer of mucosal, closed to repair, enhance the pipeline overcurrent. The use of in situ curing method for pipeline repair can extend the service life of the pipeline to 30-60 years. In-situ curing method, able to bend, variable diameter pipe repair, repair length can reach to thousands of meters. Closely attached to the wall of the resin material, can withstand the dirty water pollution of the pipeline, for high concentrations of chemical substances in the sewage can also be use.

\subsubsection{Winding method}

Winding method, mainly for the maintenance of sewage pipes, this technology is introduced from Australia to China. The winding method is mainly use of polyvinyl chloride or high concentration of polyethylene to set the edge of the parent and T-shaped bar. The pipe machine is then made into a spiral shape, into the pipe inlay lock, and sealed with silicone. Between the concrete and the spiral pipe need to inject cement slurry, this operation needs to be carried out after the pipe. The specific operation procedure of the winding method is: preparation - pipe cleaning - cctv detection - 
winding machine in place - plus lubricant - pipe winding in place - tensioning wire - gap grouting - branch - cctv detection - flood test. The use of winding method for pipeline repair, in France, Japan, Germany has been widely used in China, there are some areas also use this method and the effect is good. The use of the winding method is that the diameter of the pipe needs between $150 \mathrm{~mm}-2500 \mathrm{~mm}$, the length of the pipeline is about three hundred meters, for all types of sewage pipes, can be repaired. Winding method, for the repair of sewage pipes, has a good development prospects.

\section{The trenchless technology in urban road construction measures in the main points}

\subsection{Do the preparation of pre-construction}

Trenchless technology, before use need to do the preparatory work. For the construction of urban drainage works, the need to check the site of the project, the surrounding environment for the survey, the need to understand the layout of the pipeline, the pipeline through the regional geological conditions, and surface groundwater distribution. Only in the construction of the pipeline area to determine the geology in order to design a reasonable maintenance program, the development of the corresponding construction route map, find out the location of the hole for entry and exit, and according to geological conditions, select the appropriate pipeline maintenance technology. Only in preparation for pre-construction, in order to provide protection for the application of trenchless technology, and meet the requirements of the implementation of trenchless engineering trenchless technology, the impact on the surrounding environment to a minimum.

\subsection{Reasonable arrangements for construction}

Urban road municipal water supply and drainage works, according to the different pipeline materials, pipeline functions, and the different environment of the pipeline, the need for practical conditions and the main technical points, to develop the corresponding project maintenance program. Especially for the coffin selection, cement mortar configuration, and guide hole trajectory design. The role of urban road drainage pipes is different in the design of the pipe drawing process, the need to meet the guide hole trajectory design depth requirements, and allow the slope of the error requirements; for the calculation of the pull back, the selection of the rig, the need for "horizontal directional drilling pipeline laying engineering technical regulations" to regulate; according to the requirements of the standard pipe material selection.

\subsection{The main points of trenchless technology}

The main points of trenchless technology, including the following aspects. (1) Strict control of the axis positioning measurement, to ensure the accuracy of the data, and timely correction, adjustment. Guide the drilling operation, be sure to follow the axis positioning measurement, the use of horizontal guided drilling method. For the trenchless area of the ground, the use of guide and theodolite, the direction and depth of drilling to measure, so as to ensure the construction quality, making the laying of the spool to form a straight line. (2) In the drilling process, according to the actual situation, the drilling parameters to effectively adjust to prevent obstacles such as rocks on the drilling equipment damage. (3) Monitor the construction rules, pay attention to the structure of soil and change, to avoid the occurrence of mud loss and instability of the situation.

\section{Conclusion}

In summary, the application of trenchless construction technology in urban road construction, including the application 
of trenchless technology in the laying of new pipelines, and the application of trenchless technology in repairing old pipelines. Trenchless technology in urban road construction measures in the main points, mainly trenchless technology points, reasonable arrangements for construction, and do the preparation of pre-construction.

\section{Reference}

1. Feng Ming Shan. Trenchless Technology in Urban Water Supply and Drainage Pipeline Construction of the Main Application [J]. Private Technology, 2016,03: 154.

2. Zhang Shuo. Talking about the Main Points of Large-Scale Underground Pipeline Construction under Complex Geological Structure in Municipal Engineering [J]. Management Manager, 2016,08: 326.

3. Yu Bo, Wang Sheng. Urban Road Water Supply and Drainage of Non-Excavation of the Key Technology [J]. Building materials and decoration, 2016,34: 247-248. 